\title{
GESTÃO AUTÔNOMA E DEMOCRÁTICA: UM ESTUDO NAS ESCOLAS PÚBLICAS MUNICIPAIS DO ESTADO DE SANTA CATARINA
}

\author{
GESTIÓN AUTÓNOMA Y DEMOCRÁTICA: UN ESTUDIO EN LAS ESCUELAS \\ PÚBLICAS MUNICIPALES DEL ESTADO DE SANTA CATARINA
}

\author{
AUTONOMOUS AND DEMOCRATIC MANAGEMENT: A STUDY ON \\ MUNICIPAL PUBLIC SCHOOLS OF SANTA CATARINA STATE
}

\author{
Sulivan Desirée FISCHER ${ }^{1}$ \\ Maria do Carmo Lessa GUIMARÃES ${ }^{2}$
}

\begin{abstract}
RESUMO: O artigo analisa os fatores que favorecem e/ou constrangem a gestão autônoma e democrática a partir dos mecanismos de provimento ao cargo de diretor escolar, formação e experiência deste gestor no exercício da função. A gestão autônoma e democrática é um atributo da gestão escolar referida na LDB/96 privilegiando a ampliação da participação no processo decisório escolar, assim como a transferência de poder de decisão para o âmbito da escola, com destinação de recursos de diferentes natureza. Foram investigadas dezoito escolas municipais de ensino fundamental em seis municípios polos das mesorregiões do Estado, sendo uma escola pequena, uma escola média e uma escola grande em cada um desses municípios. A pesquisa conclui que a eleição direta para o cargo de diretor escolar, mecanismo que, segundo alguns autores, contribui para ampliar a participação na gestão das escolas, ainda não está instaurada ao interior de todas as escolas do Estado de Santa Catarina. Formação e experiência acenam favoravelmente ao exercício da função de diretor. Entretanto, parece não gerar um diferencial à institucionalização da gestão autônoma. A pesquisa aponta para desafios a serem superados na busca da institucionalização da lógica democrática que favoreça discussões em torno da questão diretiva.
\end{abstract}

PALAVRA CHAVE: Eleição diretor. Gestão Autônoma. Gestão Democrática. Gestão Escolar.

RESUMEN: El artículo analiza los factores que favorecen y/o intimidan la gestión autónoma y democrática a partir de los mecanismos de designación a la función de director de escuela, formación y experiencia de este gestor en el ejercicio de esta función. La gestión autónoma y democrática es un atributo de la gestión escolar referida en la LDB/96 privilegiando la ampliación de la participación en el proceso de toma de decisiones escolares, así como la transferencia de poder de decisión para el ámbito de la escuela, con destinación de recursos de diferentes orígenes. Fueron investigadas dieciocho escuelas municipales de enseñanza primaria en seis ciudades

${ }^{1}$ Universidade do Estado de Santa Catarina (UDESC), Departamento de Administração Pública (DAP), Pesquisadora Grupo de Pesquisa Políticas Públicas e Desenvolvimento (CALLIPOLIS/CNPq). Email: sulivan.fischer@gmail.com

2 Universidade Federal da Bahia (UFBA). Doutora em Administração; Professora Associada II. Universidade Federal da Bahia (UFBA). Email: ducalessa@ yahoo.com.br

RIAEE - Revista Ibero-Americana de Estudos em Educação, v. 11, n. 4, p. 1814-1834, 2016

E-ISSN: 1982-5587 
centrales de las mesorregiones del Estado, siendo una escuela pequeña, una escuela mediana y una escuela grande en cada uno de esas ciudades. Con la investigación se concluye que la elección directa para la función de director escolar, mecanismo que, segundo algunos autores, contribuye para ampliar la participación en la gestión de las escuelas, aún no está establecida en el interior de todas las escuelas del Estado de Santa Catarina. Formación y experiencia señalan favorablemente al ejercicio de la función de director. No obstante, parece no generar un diferencial a la institucionalización de la gestión autónoma. La investigación muestra desafíos a ser superados en la busca de la institucionalización de la lógica democrática que favorezca discusiones alrededor de la cuestión directiva.

PALABRAS CLAVE: Elección de director. Gestión Autónoma. Gestión Democrática. Gestión Escolar.

ABSTRACT: The paper analyzes the factors that contribute to and / or constrain the autonomous and democratic management from the provision mechanisms for the position of school director, training and experience of this manager on the performance of the duties. The autonomous and democratic management is an attribute of the school management stated in the LDB/96 favoring the expansion of the participation in school decision-making process, as well as the transfer of the decision-making power to the school level, with allocation of resources of different nature. Were investigated eighteen municipal elementary schools in six pole municipalities of the State's mesoregions, being one small size school, one middle size school and one big size school in each of these counties. The research concludes that the direct election for the position of school director, a mechanism that, according to some authors, contributes to broaden participation in school management, has not been introduced to all schools of Santa Catarina state. Training and experience seem favorable to the performance of the director's duties. However, it seems not to generate a differential to the institutionalization of autonomous management. The research points to challenges to be overcome in the search for the institutionalization of the democratic logic that favors discussions around the directive issue.

KEYWORDS: Director Election. Autonomous Management. Democratic Management. School Management.

\section{Introdução}

O princípio da autonomia escolar estabelecido pela $\mathrm{CF} / 88$ e posteriormente assegurados pela LDB/96, bem como em outras normativas defendidas para a gestão escolar tem provocado inúmeras discussões. Diferentes autores, a exemplo de (PARO, 1996, 2001; MARTINS, 2002; DOURADO, 2004; SILVA, 2007) abordam distintas dimensões que envolvem este princípio e reconhecem que ainda encontra-se em construção. Perseguido pelas escolas no Brasil, assim como em diversos países, a Gestão Autônoma Escolar (GAE) é um movimento internacional adotado por países 
como Nova Zelândia, Alemanha, Austrália, Chile, China, Uganda, Polônia, Rússia e Zimbábue.

Os estudos sobre a GAE tem revelado a necessidade de reestruturação do ensino público, divisão de poderes e participação mais ativa dos docentes e das famílias dos alunos nos processos decisórios. Sua materialização se dá pela transferência de poder de decisão para o âmbito da escola, com destinação de recursos de diferentes naturezas de saber, material, tempo, tecnológico, humanos e financeiros (ABU-DUHOU, 2002).

Esta estratégia descentralizada é uma evolução da política de educação e exige modificações nas estruturas de distribuição de poder, privilegiando o espaço de decisão coletiva na gestão dos assuntos escolares. Dentre as várias dimensões ou componentes, se destaca, pelo seu significado apositivo, a eleição direta para escolha do diretor escolar, na perspectiva da gestao democrática.

Reivindicada no Brasil pelos estabelecimentos escolares já nos anos 80, logo após a retomada das eleições diretas para governadores e apoiada pela sociedade e pelos movimentos sociais, em prol dos ideais democrático-participativos; foi posteriormente reafirmada, como oportunidade de consolidação da autonomia administrativa, rompendo com as indicações políticas atreladas historicamente à baganha política (PARO, 1996; TORRES; GARSKE, 2000; LIBÂNEO, 2003; BORGES, 2006; SILVA，2007; FISCHER, 2012).

Esta prevalência para a ocupação de cargos desta natureza no Brasil, sempre ocorreu por indicação principalmente de governadores, prefeitos, deputados, vereadores e Secretários de educação a pessoas com forte viés político. Contudo, as mudanças instituídas ao sistema de educação, em direção a uma gestão democrática e participativa, requerem o rompimento desta prática, que apesar do tempo decorrido e de uma série de mudanças terem sido operadas nas últimas décadas, esta antiga reivindicação não se encontra assegurada pela LDB/96. Apenas o PNE (2011/2020) estabelece como meta: “Garantir, mediante lei específica aprovadas no âmbito dos Estados, do Distrito Federal e dos Municípios, a nomeação comissionada de diretores de escola vinculada a critérios técnicos de mérito e desempenho e a participação da comunidade escolar", necessitando ser regulamentado.

Complementarmente verifica-se que esta prática ainda não está implementada, a exemplo do estado de Santa Catarina, nas escolas públicas da rede estadual, onde perdura a indicação política, e em parte das escolas municipais deste estado; assim como, pesquisas realizadas por diferentes autores, (PARO, 1996; PARENTE; LUCK, 
1999; TORRES;GARSKE, 2000; BORGES, 2006; SILVA, 2007), têm evidenciado que esta escolha dos diretores escolares, tem ocorrido utilizando diferentes estratégias e critérios; e este novo modus, nem sempre tem garantido a instauração de uma gestão mais autônoma e democrática nas escolas públicas. Isto porque, o papel desempenhado pelo diretor frente à gestão escolar têm evidenciado práticas particularistas. Entretanto, como diz Torres; Garske (2000) isso não invalida o processo.

Neste sentido, argumenta-se neste artigo que, embora na prática a eleição direta possa ter sido institucionalizada, ela não garante por si só a gestão autônoma e democrática. Os atributos de formação e experiência do diretor escolar, defendidos pela política nacional de educação básica, podem contribuir, mas não necessariamente garantem à escola uma gestão autônoma e democrática.

$\mathrm{O}$ artigo analisa os fatores que favorecem e/ou constrangem a gestão autônoma e democrática a partir dos mecanismos de provimento ao cargo de diretor escolar, tempo de docência, formação e experiência deste gestor no exercício da função gerêncial.

O estudo empírico foi realizado em 06 (seis) cidades polos de cada uma das mesorregiões do estado de Santa Catarina e em cada uma delas foram estudadas 03 (três) escolas da rede municipal de ensino fundamental, 01 (uma) escola pequena, 01 (uma) escola média e 01 (uma) escola grande. Os dados foram coletados por meio de entrevistas e questionários com diretores das escolas selecionadas e professores do ensino fundamental das séries finais. Foram também analisados os Projetos Político Pedagógico (PPP) das Unidades Escolares que fizeram esta concessão e outros documentos disponibilizados pelas escolas pesquisadas. Realizou-se um total de 18 entrevistas e foram respondidos 336 questionários entre diretores e docentes das escolas selecionadas.

Este artigo parte do debate sobre os mecanismos de escolha para o provimento do cargo de diretor escolar articulado ao papel atribuído a este gestor na construção da autonomia e democracia da gestão escolar, para em seguida apresentar os dados do estudo empírico realizado no estado de Santa Catarina. Os dados foram analisados à luz do debate sobre os pressupostos da proposta de gestão escolar explicitadas nos documentos normativos que orientam o ensino fundamental no Brasil para, em seguida, ressaltar questões centrais da pesquisa à guisa de considerações finais.

\section{Mecanismos de escolha para o provimento do cargo de diretor escolar}


Os mecanismos utilizados para o provimento do cargo de diretor escolar evidenciados por diferentes pesquisas tem sido bastante distintos (PARO, 1996; PARENTE; LUCK, 1999; SILVA, 2007), mas é a eleição o mecanismo que faz parte das políticas educacionais de segunda geração que dão ênfase à democratização da escola (PARO, 1988).

Autores como Paro (1996); Parente; Luck (1999); Dourado (2004); Silva (2007) identificaram em pesquisas realizadas variadas formas para a escolha do cargo de diretor escolar. Dentre elas destaca-se: i) indicação política; ii) acesso por carreira, iii) concurso público de provas e títulos; iv) critério misto de seleção e indicação por lista tríplice; e v) eleição direta, discutidas a seguir.

\section{Indicação Política}

Ao longo da história da política de educação no Brasil, pode-se afirmar que tradicionalmente a indicação política foi o mecanismo privilegiado de escolha para o cargo de diretor escolar. Esta prática quase "institucionalizada" ao interior das escolas públicas estaduais e/ou municipais é caracterizada pelo viés político partidário, utilizado pelos partidos políticos, em troca de apoio eleitoral. Indicação esta normalmente exercida por governadores, deputados, prefeitos e vereadores eleitos e/ou pelos partidos que compõem os arcos de aliança político partidária.

Esta prática fortemente impregnada de cultura patrimonialista, enraizada na cultura brasileira, tem a clara intenção de proteger os interesses político-partidários identificados com práticas clientelistas, favorecimento pessoal e marginalização das oposições (PARO, 1996; TORRES;GARSKE, 2000; DOURADO, 2004).

Esta influência do agente político, obviamente, não se dá apenas na nomeação para o cargo de diretor, diz Silva (2007), ela ocorre também durante o exercício do mandato do diretor, em que pressões por práticas clientelistas são exercidas pelos agentes políticos para fazer valer seus interesses (PARO, 1996).

Silva (2007) ainda ressalta que os diretores, por sua vez, tendem a desenvolver obediência aos agentes políticos do partido que os indicou, em detrimento aos anseios vindos da comunidade escolar. Da mesma forma, o autor refere ter constatado em suas pesquisas o uso de expedientes de coerção, por alguns diretores, denunciando 
profissionais da educação que se mostram contrários às atitudes do governo, realizando a remoção do profissional e/ou sua colocação à disposição da Secretaria de Educação.

Atitudes autoritárias, algumas vezes arbitrárias e diretivas, em anuência à política ideológica do partido, na luta pela manutenção no cargo são relatadas por autores como PARO (1996, 2003), DOURADO (2004) e SILVA, (2007).

Esta modalidade, articulada ao conservadorismo político, segundo Dourado (2004), ainda é encontrada em estados e municípios brasileiros. Em alguns casos, diz Paro (1996) há um refluxo das eleições para diretores de escola, em alguns estados, que entraram com Ações Diretas de Inconstitucionalidade contra as eleições direta para direção escolar retomando o critério de indicação política.

\section{Acesso por Carreira}

O acesso ao cargo de diretor escolar por carreira é uma modalidade pouco utilizada no Brasil e segue critérios tais como: formação escolar, tempo de serviço, merecimento ou distinção, estabelecidos pelo ente federativo (estados e municípios) (DOURADO, 2004). Essa modalidade está pautada no modelo de gestão burocrático, baseado na meritocracia, mas também na obediência às funções estabelecidas para o exercício do cargo, onde o elemento direcionador do trabalho do diretor é a norma legal, e seu descumprimento poderá acarretar sanções que prejudicarão sua carreira (SILVA, 2007). Essa interferência pode também neutralizar iniciativas em busca de uma gestão autônoma e democrática, pela exclusão da comunidade de participar da escolha do dirigente escolar.

Nesta modalidade, as normas e regulamentos estabelecidos a priori em avaliação ao desempenho do gestor escolar tende a limitar sua ação discricionária, assim como, diz Silva (2007), transformar a administração escolar numa tarefa burocrática e centralizada.

Considerando a assertiva apontada por Cury (2002) de que a escola enfrenta problemas que não são da escola, mas que estão na escola, e, neste sentido, precisam ser resolvidos, o exercício discricionário na função de gestor escolar é primordial para tomar decisão com dinamismo para a resolução dos problemas escolares, ainda que respeitados os limites da lei e em defesa da ordem pública.

O acesso por carreira, na visão de Dourado (2004), é uma variação da indicação política, apesar de parecer fundado no mérito das pessoas. Ele exclui a comunidade de 
participar da escolha do dirigente escolar, instiga à acomodação do indivíduo por sua função vitalícia e pode cristalizar a gestão pela permanência do indivíduo no cargo e sua acomodação na carreira, fatores contrários à gestão autônoma e democrática escolar, que exige participação e ações transformadoras como prática permanente.

\section{Concurso público de Provas e Títulos}

Em defesa da modalidade de Concurso Público para nomear diretor escolar, alguns interlocutores têm o feito por creditar a esse processo a objetividade na escolha que se faz baseada em méritos intelectuais (DOURADO, 2004). Nele, os candidatos são submetidos a prova de conhecimentos específicos para o exercício do cargo, onde o resultado produz uma classificação que será somada à contagem de seus títulos (SILVA, 2007). Esta modalidade põe em evidência para escolha ao exercício do cargo de diretor escolar a dimensão técnica. No entanto, sabe-se que a gestão escolar não está reduzida à técnica administrativa em observância única e exclusivamente as regras préestabelecidas sobre o que fazer, do como gerenciar e quais procedimentos e instrumentos devem ser utilizados (DOURADO, 2004; SILVA 2007, FISCHER, 2012).

A rigor, uma gestão escolar autônoma e democrática exige outras competências deste gestor, relacionada às dimensões política e social, caracterizando a gestão escolar como um fenômeno multidimensional, diz Junquilho (2001), que sofre influências tanto do ambiente interno como externo.

Desta assertiva, compreende-se a gestão como um fenômeno sistêmico, onde os componentes estão inter-relacionados e são dependentes um do outro, o que requer do profissional que estiver desempenhando a função de diretor escolar, habilidades interpessoais tais como de mediação de conflitos, liderança, articulação com a comunidade. Tais habilidades parecem difíceis, a princípio, de serem medidas por meio de provas de conhecimento específico e pela comprovação de títulos.

Outro ponto criticado por Paro (1996) a esta modalidade é a vitalicidade que o concurso proporciona ao diretor, contribuindo para a acomodação do profissional e um possível descompromisso deste com os objetivos educacionais articulados com a comunidade e a gestão democrática.

Silva (2007) também critica esta modalidade, pois ela concorre com a prática democrática de escolha do diretor pela comunidade. Ainda que pareça democrática pela 
possibilidade de tratamento igualitário oferecido a todos os candidatos diante da oportunidade de ocupar o cargo pelo atendimento aos requisitos técnicos estabelecidos, esta prática não é democrática para a escola que não pode escolher seu diretor.

Dourado (2004) compreende como salutar o concurso público para ingresso na carreira de docente no serviço público, como ponto de partida para o ingresso no sistema de ensino, onde após efetiva contribuição à comunidade escolar, possa este servidor vir a se candidatar ao cargo de dirigente escolar pautado em mecanismo de escolha democrático.

\section{Critério misto de Seleção e Indicação por Lista Tríplice}

O critério de indicação por lista tríplice consiste na consulta à comunidade escolar para indicação de nomes para ocupar o cargo de diretor escolar. $\mathrm{O}$ executivo nomeia o diretor dentre os nomes destacados e/ou submete a uma segunda fase, (critério misto), que consiste de provas ou atividades de avaliação de sua capacidade cognitiva para a gestão escolar. Esta modalidade conta com a participação da comunidade escolar apenas no início do processo, na medida em que cabe ao Executivo deliberar sobre a indicação do diretor, o qual pode estar fundamentado em critérios diversos (DOURADO, 2004).

PARO (1996) destaca em pesquisa realizada por diferentes autores, certa permanência da influência político-partidária mesmo nesta modalidade, com iniciativas dos grupos de pressão para nomeação de determinados candidatos, caracterizando prática clientelista.

Para Dourado (2004) o importante é identificar, quando do uso desta modalidade, se o papel desenvolvido pela comunidade escolar é decisivo ou não, isto é, se ela apenas legitima o processo amparado no discurso da participação e democratização escolar.

\section{Eleição Direta}

A eleição direta é uma das manifestações de gestão escolar autônoma e democrática mais presentes na escola pública, que não apenas marcou, mas ainda marca o movimento em defesa da democratização da educação no país. Seu destaque está fundado no alinhamento que esta modalidade tem com a democracia, que impingiu no 
imaginário da população brasileira a crença de que esta modalidade neutralizaria as práticas clientelistas, reduziria o favorecimento pessoal, eliminaria o autoritarismo existente na escola, ampliando a participação dos professores, pais e alunos nas decisões dos assuntos escolares, garantindo assim serviços de melhor qualidade e ficando imune às práticas corporativistas de grupos que interagem com a escola (PARO, 1996, 2001; DOURADO,2004; SILVA, 2007).

Esse mecanismo de eleição direta tem sido institucionalizado pelos estados e municípios em formatos distintos, sendo comum para essa forma de provimento a votação direta e a seleção com eleição (DOURADO, 2004).

$\mathrm{Na}$ votação direta a escolha é realizada pelo colégio eleitoral e o candidato com maior número de votos assume o cargo de acordo com o período definido regimentalmente. Já na seleção e eleição, o processo combina algum tipo de critério "a priori” constituído, por exemplo: de provas e títulos e/ou apresentação de plano de trabalho. Satisfeitos os critérios, os candidatos classificados inscrevem-se para participar do processo eleitoral de determinada escola. Neste momento, a comunidade escolhe através de eleição o diretor escolar (DOURADO, 2004; SILVA, 2007).

A despeito do formato de seleção e eleição, (SILVA, 2007) adverte que críticas tem surgido a essa forma, pela limitação ao número de candidatos que disputarão o processo eleitoral resultante da seleção "a priori”. Por outro lado, a eleição direta, apesar de enaltecida por realçar a democracia e ter sido assimilada pela população brasileira como um valor positivo, também têm apresentado limitações, diz Paro (1996, 2001). As pesquisas tem constatado que em alguns sistemas educacionais, a influência política continua a persistir, e práticas clientelistas perduraram mesmo após a institucionalização do mecanismo de eleição direta.

Para tanto (PARO, 2001) adverte que a neutralização de práticas clientelistas se darão com a participação mais efetiva da comunidade (professores, técnicos, pais e alunos); e o exercício autônomo da cidadania, em rompimento com a cultura tradicional patrimonialista. Nesse sentido, a eleição direta é apenas um dos componentes que podem influir para a gestão escolar se tornar mais autônoma e mais democrática. $\mathrm{O}$ modo de agir do diretor, sua conduta e especialmente seu compromisso com os anseios da comunidade e o grau de envolvimento e de participação dos atores nas ações escolares, como sujeitos politicamente autônomos, parecem caracterizar-se como alguns atributos que podem possibilitar a escola uma gestão mais autônoma e mais democrática. 
Neste sentido, parece salutar discutir os significados da gestão escolar e as novas atribuições inerentes ao cargo de diretor na perspectiva da construção de uma escola autônoma e democrática.

A expressão autonomia no âmbito escolar, segundo Dourado (2004), a partir dos enunciados de Barroso, é sempre relativa, uma vez que é condicionada pelos poderes públicos e pelo contexto em que se efetiva. Esta autonomia significa transferir atribuições e competências para a escola resolver seus problemas de acordo com os anseios e necessidades da comunidade, que para tal, vincula-se à ideia de participação social e/ou ampliação da participação política, a qual é construída cotidianamente (MARTINS, 2002; DOURADO, 2004; FISCHER, 2012).

Para tanto, uma nova cultura precisa ser institucionalizada, apoiada em novos mecanismos de escolha para o cargo de diretor, implementando instâncias colegiadas de gestão para o partilhamento do poder; possibilitando novos aprendizados para o corpo funcional, diretor, professores e técnicos, assim como para a comunidade de pais e alunos. Esta nova concepção de escola autônoma e democrática exige maior envolvimento, maior participação, maior responsabilização dos atores, que passam a coproduzir com a escola em busca de alternativas que possibilitam melhor qualidade no ensino.

Neste contexto, o diretor assume papel significativo na implementação desta cultura, devendo porta-se como ser político e social, nesta relação com os diferentes atores. Buscando a conciliação e o consenso, atuando como articulador, representando a escola perante as instâncias superiores.

\section{O processo de provimento do cargo de diretor escolar: Resultados do estudo empírico}

\section{Os critérios e mecanismos de escolha para diretor escolar}

Esta pesquisa identificou a existência de diferentes mecanismos utilizados para a escolha do provimento do cargo de diretor escolar nos municípios do Estado de Santa Catarina, a exemplo de eleição direta, seleção e eleição, indicação técnica e indicação política. Alguns diretores citaram outra forma "distinta" de escolha 
dos diretores, a qual, após análise mais aprofundada do seu conteúdo, concluiu-se tratar de "indicação política", e por esta razão, foi computada como tal.

Do universo das 18 (dezoito) escolas pesquisadas, 10 (dez) escolas adotam a eleição direta para provimento do cargo de diretor escolar. Estas escolas estão localizadas no município de Florianópolis; Blumenau; Criciúma e Lages. Contudo, verificou-se que, apesar da institucionalização da eleição direta vigorar, em uma das escolas do município de Lages investigadas, evidenciou-se uma longa permanência do gestor no exercício do cargo. Caracterizando a institucionalização da reeleição, fragilização do processo da eleição direta e da alternância do poder, tão salutar para a consolidação democrática.

Apesar dessa constatação, não foi possível, nesta pesquisa, investigar mais profundamente os desdobramentos deste processo, e seus efeitos. Também no município de Lages, constatou-se em outra escola pesquisada, que o processo de escolha para diretor sofreu alternância entre o critério da indicação política e a eleição direta ao longo desses anos, evidenciando a não consolidação deste processo. Recentemente, para a gestão 2010/2012, foi realizada novamente a eleição direta com a participação da comunidade escolar interna e externa. Desde a criação da escola, verificou-se que apenas duas vezes foi adotado o mecanismo de eleição direta para o provimento do cargo de diretor escolar, sendo a indicação e nomeação direta pelas lideranças político partidárias mais frequentes nesta escola.

Estas idas e vindas da nomeação do cargo de diretor escolar sempre foi e continua sendo um assunto bastante polêmico, visto que a eleição direta diminui a capacidade dos políticos interferirem na vida cotidiana da escola (PARO, 1996; BORGES, 2006).

Desta visão compartilham docentes que participaram desta pesquisa:

A questão político partidária interfere fortemente na tomada decisão da escola, reduzindo a autonomia e dificultando a ação da escola no desenvolvimento de um trabalho de melhor qualidade (Docente, abril de 2012).

Apesar da institucionalização da eleição direta para escolha de diretores em 10 (dez) escolas, quando da análise dos Projetos Político Pedagógico (PPPs), constatou-se variação na participação dos atores nas eleições para diretores. Dentre as escolas que adotam a eleição direta, verificou-se, por exemplo, numa escola do município de Criciúma descrito no seu PPP que: "a escolha para Diretor Escolar é realizada com a 


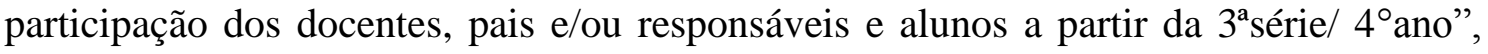
excluindo-se os técnicos desta escolha.

Chama a atenção as características dos registros observados nos PPPs e em outros documentos da maior parte das escolas pesquisadas, caracterizando a participação na "eleição pelo voto direto da comunidade interna e externa", como o critério mais utilizado. No entanto, não foi identificado em grande parte dessas escolas quem são os atores aptos a votarem, informação que deve constar dos editais de convocação para a eleição. Contudo, não se teve acesso a esses editais, sob a justificativa de que este documento está sob a responsabilidade da Secretaria de Educação do Município.

Outra forma identificada pela pesquisa para a escolha do cargo de diretor escolar fora o critério misto, seleção e eleição, embora referido em apenas uma das escolas pesquisadas no município de Blumenau. Ainda assim, o diretor escolar ao explicitar que a forma para escolha do cargo de diretor tenha sido o critério de seleção e, posteriormente a eleição, não citou os critérios observados para a seleção, se políticos e/ou técnicos. Além disso, a maioria dos docentes desta escola, $66,7 \%$ não cita o critério de seleção, destacaram apenas que a forma para escolha de diretor foi a eleição direta.

Ainda é importante observar que nas escolas onde a escolha se dá pela eleição direta, não foi identificado e explicitado pelos diretores se a eleição direta esteve acompanhada das regras preconizadas pelo MEC, no novo PNE 2011-2020, no que diz respeito a observação de critérios técnicos.

Esta vinculação foi encontrada apenas em escolas que não utilizam a eleição direta como mecanismo para escolha para o provimento do cargo de diretor escolar. Este achado foi encontrado somente em uma das escolas pesquisadas no município de Joinville, e foi confirmada por $100 \%$ dos docentes que participaram da pesquisa, o que, em princípio adquire validação. Esta forma adotada nesta escola é distinta em relação às outras duas escolas pesquisadas no mesmo município, que segundo os diretores foi indicação.

Contudo, ao analisar com mais acuidade o depoimento a seguir transcrito da diretora desta referida escola, é possível constatar que tal escolha se deu tanto pela observação de critérios técnicos objetivos, a exemplo do tempo de exercício na rede municipal, quanto por critérios mais subjetivos, isto é, a indicação ou "aval" da Secretaria de Educação, por considerar este cargo como "de confiança": 
O profissional deve ser concursado, ter 05 (cinco) anos de exercício na rede municipal, ter os requisitos solicitados para o cargo, como titulação. A indicação acontece através da Secretaria municipal de Educação, pois é caracterizado como cargo de confiança. (Entrevista diretor, maio 2012).

Neste particular é necessária uma observação metodológica quanto à tarefa analítica aqui empreendida. Os resultados obtidos por meio dos informantes-chave desta pesquisa, sobre a utilização de critérios, técnicos ou políticos, para o provimento do cargo de diretor da escola, partiram de duas premissas. Existe uma dificuldade "compreensível" de o diretor se referir a sua indicação para o cargo, sem observar critérios técnicos, pois isto o desqualificaria. Segundo, admitir indicação política, o coloca numa condição de "apadrinhado", o que é, em certa medida, e para determinada audiência, também uma desqualificação. Nesse sentido, as informações extraídas do depoimento dos diretores sobre possíveis critérios de indicação para o cargo que ocupa, foram aqui analisados, triangulando com as informações fornecidas pelos docentes e com as extraídas de documentos sobre a mesma questão. É nesta triangulação que esta discussão adquire relevância.

Da mesma forma, a evidência de indicação política para a direção de uma das escolas pesquisadas no município de Chapecó foi confirmada, tanto pela diretora, quanto pelos docentes, quando $86,2 \%$ dos docentes confirmaram ter sido este o critério observado.

Verificou-se ainda, em outra escola do município de Chapecó, que, apesar da diretora ter destacado que a escolha para o cargo de direção obedeceu a critérios técnicos, $82,4 \%$ dos docentes que participaram da pesquisa não confirmaram essa informação, afirmando o contrário, que o critério foi o da indicação política. Neste caso particular, é interessante também observar, que, na visão do diretor desta escola, a interferência política recai sobre a prática do docente, considerando, inclusive, ser um dos fatores que interfere diretamente na gestão da escola, a falta de separação entre sigla partidária e educação, como ilustra seu depoimento: "Alguns professores não conseguem separar sigla partidária da educação como objetivo único" (Entrevista diretor, maio 2012).

Vale ressaltar que contradições observadas sobre os critérios de escolha para o cargo de direção, entre a visão dos diretores e dos docentes, foram recorrentes.

Em outra escola, também do município de Chapecó, a diretora informou que a escolha para o cargo de diretor se deu por indicação da gestora de outra escola do 
mesmo bairro, o que, para $81,8 \%$ dos docentes foi considerado como critério de indicação política.

Situação similar foi evidenciada em outra escola no município de Joinville, onde o diretor considerou que sua indicação para o cargo se deu através de outros gestores com quem ele já havia trabalhado. Contudo, 74,2\% dos docentes desta escola que participaram da pesquisa, confirmaram que o processo de escolha para o cargo de diretor escolar foi o da indicação política.

Outras formas de indicação para o provimento do cargo de diretor escolar foram também relatadas, a exemplo de outra escola do município de Joinville, em que a diretora referiu que sua indicação partiu da Associação de Pais e Professores (APP), dos docentes e do Diretor escolar anterior à Secretaria Municipal de Educação. Contudo, esta informação foi confirmada por apenas 47,4\% dos docentes, enquanto $26,3 \%$ a identificam como sendo por indicação política, 15,8\% como um processo seletivo (inespecífico) e 10,5\% não responderam. Esses resultados revelam falta de clareza sobre os critérios para a escolha para o cargo de diretor escolar.

No universo das 18 (dezoito) escolas pesquisadas foi identificada uma situação particular em relação ao processo de escolha da direção escolar em uma escola do município de Criciúma. Nesta escola, não há diretor escolar, existe uma auxiliar de direção indicada e nomeada pelo município, servidor estatutário da carreira do magistério municipal, que representa a escola perante os órgãos oficiais do governo, principalmente federal, para recebimento de verba, sendo a interlocutora entre a Escola, o município e o MEC, além de um Coordenador geral indicado pelo Conselho Diretor do Bairro.

A pesquisa evidenciou também que, em algumas escolas, os respectivos diretores estão no cargo há muitos anos, evidenciando o fenômeno da reeleição que parece se constituir em prática recorrente nos municípios estudados. Foi verificado o instituto da reeleição em escolas dos municípios de Lages, de Chapecó e de Criciúma.

Sobre esta situação e com base nos dados levantados pela pesquisa, é possível inferir que este instituto da reeleição possa estar relacionado com as seguintes situações: a acomodação por parte dos docentes que não se candidatam à vaga nas escolas onde o mecanismo utilizado é a eleição direta, caracterizando uma baixa participação e envolvimento dos profissionais; ou, nas escolas onde o mecanismo de escolha para o cargo de diretor é a indicação política, esta prática tradicional inibe a participação e 
candidatura de novos atores; ou, ainda, há cooptação pelo gestor que se encontra no cargo inibindo a escolha livre fundada no princípio de autonomia individual.

Torres e Garske (2000) alegam, para que a participação encontre o seu lugar, é preciso modificar a lógica interna da escola, alterando as relações de poder e reorganizando-a em bases mais igualitárias, em que todos podem e devem participar ativamente. Conclui-se, então, que a participação não se restringe apenas ao voto para escolha do diretor, mas ao exercício da função, por meio da alternância dos gestores, distribuindo o poder entre os diferentes atores, ao invés de concentrá-lo única e exclusivamente sempre nas mãos das mesmas pessoas.

Vale lembrar, entretanto, ainda que reconheça a importância da institucionalização de estratégias participativas para o provimento do cargo de diretor, o argumento de PARO (1996, 2001) ao considerar que, nem sempre esta institucionalização assegura, por si só, uma gestão escolar mais democrática e participativa, pois isso também depende do comportamento do diretor no exercício da sua função como gestor.

Os resultados sobre os mecanismos utilizados para o provimento do cargo de diretor escolar, aqui ilustrados com os dados das escolas nos municípios que integram o universo desta pesquisa, reforçam o ainda incipiente processo de participação da comunidade escolar na escolha dos seus gestores, o que num certo sentido contribui para fragilizar a gestão democrática. Tais resultados apontam para a falta de transparência em relação aos critérios adotados para o provimento deste cargo em muitas escolas e o privilegiamento de critérios de natureza particularista.

Das análises realizadas em relação à eleição direta para o cargo de diretor escolar, considerado um mecanismo que contribui para ampliar a participação na gestão das escolas, conclui-se que este mecanismo ainda não está instaurado em todas as escolas do Estado de Santa Catarina.

Outros constrangimentos à autonomia e à participação nas escolas pesquisadas foram identificados em relação aos recursos humanos. Fatores considerados relevantes para esta pesquisa e para o exercício da gestão, como formação dos dirigentes, sua capacitação técnica e participação em cursos e projetos de educação continuada, bem como o tipo de vínculo trabalhista, aliado à experiência em gestão, discutidos a seguir.

\section{O perfil dos diretores das escolas municipais: educação continuada, experiência em gestão e tipo de vínculo trabalhista}


Conforme definido pelo PNE 2001-2010, para o exercício da função de diretor escolar, a formação, assim como a experiência, são fatores que infuenciam positivamente na gestão: "Assegurar formação em nível superior e preferencialmente de especialização dos diretores [...] Estabelecer programas diversificados de educação continuada e atualização para o cargo de diretores de escolas” (MEC, 2011).

Considerando a recomendação do PNE 2001-2010, esta pesquisa investigou a formação regular e continuada dos gestores nos últimos dois anos, a experiência na área de educação e no exercício do cargo de diretor escolar, bem como o vínculo funcional dos diretores das 18 escolas pesquisadas.

A pesquisa evidenciou que todos os diretores escolares possuem nível superior e que destes, 11 (onze) são formados em pedagogia, 04 (quatro) em outras áreas do conhecimento e (03) três licenciados em Letras. Somente 01 (um) destes diretores tem dupla formação, Licenciatura em Letras e Direito.

Constatou-se também, que todos os atuais diretores das escolas pesquisadas possuem no mínimo uma especialização de 360 horas. Destes, 06 (seis) realizaram a especialização em Educação com foco em Gestão e Administração Escolar. Há somente (01) diretor com pós-graduação stricto sensu em nível de doutorado - em educação com foco em outras áreas.

Somado à formação regular, esta pesquisa constatou que em 16 (dezesseis) das 18 (dezoito) escolas pesquisadas, os diretores realizaram educação continuada. Contudo, na avaliação dos diretores que participaram da pesquisa, estes cursos não têm agregado muito à sua prática, que se ilustra por um depoimento de um diretor:

Têm sido oferecida normalmente pela Prefeitura por intermédio da Secretaria de Educação que para a maioria nem sempre têm contribuído, pois as informações apresentadas nos cursos de formação quase sempre já são do seu conhecimento e/ou estão desatualizadas e muitas vezes falta integração dos conteúdos com a prática encontrada no ambiente escolar, o que desta forma, é considerado pelos diretores como repasse de informações irrelevantes (Entrevista diretor, maio, 2012).

Dentre estes 16 (dezesseis) diretores escolares que realizaram educação continuada nos últimos dois anos, 10 (dez) realizaram mais de 80 horas de curso. 
Além da formação profissional específica e sua atualização explicitados pela Legislação, a capacidade de gestão e o conhecimento sobre questões pedagógicodidáticas são, para Libâneo (2003), requisitos desejáveis para o gestor ocupante do cargo de diretor escolar. Esta assertiva de Libâneo (2003) aponta para capacidades que podem ser adquiridas por meio da experiência na educação e no exercício do cargo de direção.

Esta pesquisa constata, a partir da análise das informações, que, no universo das 18 (dezoito) escolas pesquisadas, os diretores escolares atuais trabalham no há mínimo 11 anos e alguns a mais de 15 anos na educação.

Foi ainda verificado que quase a totalidade dos diretores são estatutários, somente 01 (uma) diretora é comissionada e 01 (um) tem contrato pela CLT. Em relação ao tempo de exercício na função de direção, a pesquisa verifica que das 18 escolas pesquisadas existem 04 (quatro) diretores que exercem funções de direção há menos de dois anos, tempo que corresponde aquele do exercício do cargo na unidade escolar atual. Isto é, primeira experiência como diretor escolar.

Foi verificado também, em outras 04 (quatro) escolas, que os diretores estão exercendo a função de diretor, na mesma escola, entre dois a quatro anos. Ou seja, apesar da experiência ser um pouco mais ampliada, se comparada aos quatro primeiros diretores descritos que estão no exercício do cargo há menos de dois anos, a experiência deste grupo de diretores é similar, pois o tempo para o exercício no cargo de diretor escolar entre as escolas pesquisadas varia entre dois e três anos. Caracterizando o exercício da função também como primeira experiência.

Também se verificou que há 05 (cinco) diretores que exercem a função de diretor por um período entre cinco e dez anos. Entretanto, somente três dos cinco diretores permanecem o mesmo tempo no exercício da função de diretor na mesma escola. Dos outros dois que exercem a função de diretor entre cinco e dez anos, um deles é diretor na unidade escolar atual há menos de 2 anos. Isto é, apesar de sua experiência maior na função, na escola atual esta é a sua primeira experiência como gestor.

Foi identificado, ainda, que outros 04 (quatro) diretores escolares exercem a função de direção entre 11 e 15 anos. Entretanto, destes diretores somente uma diretora, no município de Joinville, exerce a função de direção numa nova escola.

Em entrevista com esta diretora, a mesma salientou o desafio atual, pois apesar de já ter sido diretora em outras unidades escolares do município, esta é a primeira vez 
que está à frente de uma escola de pequeno porte, o que tem exigido novas competências, pois os recursos são mais escassos. Ao mesmo tempo, diz a diretora, sua interação com os docentes passou a ser maior, em face da sua necessidade em adquirir conhecimento sobre a realidade da escola.

Por fim, identificou-se que 01 (um) diretor numa das escolas do município de Lages, está há mais de 15 anos exercendo a função de diretor escolar na mesma unidade, caso mais emblemático de permanência no poder por meio do instituto da reeleição encontrado no universo desta pesquisa.

\section{Considerações finais}

Os resultados desta pesquisa evidenciam que embora seja uma recomendação do novo PNE 2011-2020 a necessidade de investir em formação dos diretores escolares em nível de pós-graduação stricto sensu, visando contribuir para uma melhoria na qualidade do ensino e de práticas inovadoras, apenas um diretor dos que participaram desta pesquisa possui tal formação. Em contrapartida, é relevante a constatação feita por esta pesquisa, de que, nas escolas dos municípios do Estado de Santa Catarina, a grande maioria dos diretores possui uma formação regular adequada, tem vínculo trabalhista permanente (são estatutários) e muitos têm experiência em gestão. Estes achados apontam para um cenário favorável ao exercício da função, ainda que reconheça que a construção de uma gestão autônoma e democrática não se defina apenas por esses indicadores.

Estudos sobre a gestão escolar autônoma e democrática apontam que a dependência financeira e normativa das unidades escolares às outras esferas de governo, em particular federal e municipal, o limitado poder de decidir sobre a aplicação dos recursos, parecem, em princípio, absorver estes atributos pessoais dos dirigentes, não gerando um diferencial no processo de condução na gestão do ensino no âmbito escolar. Ou seja, formação e experiência no cargo são atributos que contribuem, mas não asseguram isoladamente uma gestão autônoma escolar.

Há que observar também que, apesar da pesquisa ter evidenciado elevada experiência no exercício do cargo de diretor escolar nas escolas investigadas, há gestores ocupando a função na escola atual pela primeira vez, o que impõe novos 
desafios ao gestor escolar; pela falta de conhecimento dos assuntos da escola e dos anseios da comunidade escolar.

Evidenciou-se que, na atualidade, todos os municípios pesquisados têm investido em cursos de educação continuada. Neste particular, os resultados revelam pouca significância dos cursos atribuída pelos diretores, ao considerarem que lhes falta profundidade sobre os assuntos tratados, por terem uma carga horária reduzida e considerarem que pouco contribuem para o exercício da atividade no cargo de diretor.

Desta forma, concluiu-se que este expediente de valorização profissional, utilizado pelas instâncias federal e municipal, buscando estimular a educação continuada dos profissionais, ainda não encontrou um denominador comum, pois não está sendo visto pelos profissionais como estratégico para a melhoria do seu desempenho.

De outro modo, os critérios para escolha do cargo de diretor, mais especificamente a eleição direta, têm sido vistos como indicadores importantes da autonomia e participação na gestão escolar. A eleição direta é considerada pela política nacional de educação, e respaldada pela literatura, como o primeiro degrau em direção à ampliação da participação na gestão das escolas. Os achados da pesquisa nos municípios do Estado de Santa Catarina apontam para a existência de critérios técnicos e políticos e em alguns casos a existência da eleição direta para o provimento do cargo de diretor escolar. Contudo, tais resultados revelam um ainda incipiente processo de participação da comunidade escolar na escolha dos seus gestores, e reforçam a falta de transparência em relação aos critérios adotados para o provimento deste cargo em muitas escolas, em face do privilegiamento de critérios de natureza particularista. A permanência destes critérios, bem como a existência do instituto da reeleição como forma de permanência no poder de alguns diretores escolares, evidenciados pela pesquisa, apontam para desafios a serem superados na busca da institucionalização da lógica e de mecanismos democráticos que favoreçam o aprofundamento das discussões em torno da questão diretiva.

\section{REFERÊNCIAS}

ABU-DUHOU, Ibtisam. Uma gestão mais autônoma das escolas. Brasília: UNESCO, IIEP, 2002. 
BORGES, André. Governo estadual, competição política e mudança institucional: Lições comparativas da reforma da gestão escolar no Brasil. In: SOUZA, Celina; DANTAS NETO, Paulo Fábio (Org.). Governo, políticas públicas e elites políticas nos estados brasileiros. Rio de Janeiro: Revan, 2006.

BRASIL. Lei n. 9.394, de 20 de dezembro de 1996. Estabelece as diretrizes e bases da educação nacional. Diário Oficial [da] República Federativa do Brasil, Brasília, DF, 1996. Disponível em: <http://www.planalto.gov.br>. Acesso em: 10 jan. 2009.

Projeto de Lei: Plano Nacional de Educação para o decênio 2011-2020 (PNE 2011/2020). Congresso Nacional. Brasília, DF, Disponível em: $<$ http://portal.mec.gov.br/index.php?option=com_content $\&$ view $=$ article $\&$ id $=16478 \&$ Ite $\operatorname{mid}=1107>$. Acesso em: 30 mai. 2010.

. Lei n ${ }^{\circ} 11.172$, de 9 de janeiro de 2001. Aprova o Plano Nacional de Educação e dá outras providências. Diário Oficial [da] República Federativa do Brasil. Brasília, DF, 10 dez. 2001. Disponível em:<http:www.planalto.gov.br>. Acesso em: ago. 2011.

CURY, C.R.J. Gestão democrática da educação: exigências e desafios. Revista Brasileira de Política e Administração da Educação, São Bernardo do Campo, v. 18, n. 2, jul./dez. 2002.

DOURADO, Luís Fernandes. Conselho Escolar, gestão democrática da educação e escolha do diretor. 1. ed. Brasília-DF: MEC/SEB, 2004.

FISCHER, Sulivan Desirée. Implementação da Política Descentralizada de Ensino Fundamental: um estudo sobre a gestão escolar em Municípios do Estado de Santa Catarina. 2012. 279f. Tese (Doutorado em Administração) - Núcleo de Pós-Graduação em Administração, Universidade Federal da Bahia, Salvador, 2012.

JUNQUILHO, Gelson Silva. Gestão e ação gerencial nas organizações contemporâneas: Para além do "folclore" e do "fato". Revista Gestão e produção, v.8, n³, p.304-318, dez. 2001.

LIBÂNEO, José Carlos. Educação Escolar: políticas, estrutura e organização. São Paulo: Cortez, 2003 (Coleção Docência em Formação). Coordenador Antonio Joaquim Severina, Selma Garrido Pimenta.

MARQUES, M. Administração pública: Uma abordagem prática. Rio de Janeiro: Ferreira, 2006.

MARTINS, Ângela M. Autonomia e descentralização: a (ex)tensão do tema na agenda das políticas públicas educacionais recentes. Revista Portuguesa de Educação, 15(1), p.269-296, 2002.

PARENTE, Marta Maria de A.; LUCK, Heloísa. Mapeamento da descentralização da educação brasileira nas redes estaduais do ensino fundamental. Rio de Janeiro, Ipea, out. 1999. 
PARO, Vitor H. Eleição de diretores de escolas públicas: avanços e limites da prática. Revista Brasileira de Estudos Pedagógicos, Brasília, DF, v.77, n.186, p.376-395, mai/ago, 1996.

PARO, Vitor H. Gestão Democrática da escola pública. São Paulo: Ática, 1998.

PARO, Vitor H. Escritos sobre educação. São Paulo: Xamã, 2001.

PARO, Vitor H. Eleição de diretores: a escola pública experimenta a democracia. São Paulo: Xamã, 2003.

SILVA, N.R.G.. O diretor de escola e a gestão democrática: a influência dos meios de acesso ao cargo de dirigente escolar. Revista Educação, v.10, n.10, 2007.

TORRES, Artemis; GARSKE, Lindalva M.N. Diretores de escola: o desacerto com a democracia. Em aberto, Brasília, v.17, n.72, p.60-70, fev.jun.2000.

\section{Como referenciar este artigo}

FISCHER, Sulivan Desirée.; GUIMARÃES, Maria do Carmo Lessa Guimarães. Gestão autônoma e democrática: um estudo nas escolas públicas municipais do Estado de Santa Catarina. Revista Ibero-Americana de Estudos em Educação, Araraquara, v. 11, n. 4, p. 1814-1834, 2016. Disponível em: 〈http://dx.doi.org/10.21723/riaee.v11.n4.6133>. EISSN: 1982-5587.

Recebido em: agosto/2013

Aprovação final em: julho/2016 